\title{
Iron deficiency anemia in older adults: A review
}

\author{
Etienne Joosten (1) \\ Department of Internal Medicine, Division of Geriatric Medicine, University Hospitals Leuven, Leuven, Belgium
}

\begin{abstract}
Anemia in older adults is a risk factor for numerous negative outcomes. There is no standard definition, but in most studies, anemia is defined as a hemoglobin value $<12 \mathrm{~g} / \mathrm{dL}$ for women and $<13 \mathrm{~g} / \mathrm{dL}$ for men. Absolute iron deficiency anemia is defined as the combination of anemia and the absence of total body iron. Serum ferritin is the most frequently used diagnostic parameter, but its concentration increases with age and in the presence of inflammatory diseases. Other laboratory tests, such as transferrin saturation, soluble transferrin receptor and the soluble transferrin receptor/ferritin index might provide useful information, but there is a wide variety in the cut-off values and interpretation of the results. Recent research regarding hepcidin as a central regulator of iron homeostasis is promising, but it has not been used yet for the routine diagnosis of iron deficiency anemia. In older iron deficiency anemia patients, an esophagogastroduodenoscopy and colonoscopy should be initiated in order to identify the underlying bleeding cause. CT colonography can replace a colonoscopy, and in specific cases, a video capsule is recommended. It remains crucial to keep in mind which potential benefits might be expected from these investigations in this vulnerable population, taking into account the comorbidity and life expectancy, and one should discuss in advance the possible therapeutic options and complications with the patient, a family member or a proxy. Oral iron administration is the standard treatment, but parenteral iron is a convenient and safe way to provide the total iron dose in one or a

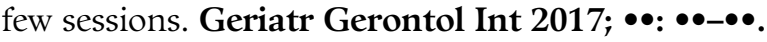

Keywords: anemia, iron deficiency anemia, older adults, review.

\section{Introduction}

Anemia is a common clinical problem in older adults. It is mostly defined according to the World Health Organization criteria as a hemoglobin value $<12 \mathrm{~g} / \mathrm{dL}$ in women and $<13 \mathrm{~g} / \mathrm{dL}$ in men, although others have proposed lower age-adjusted values for hemoglobin to define anemia. ${ }^{1,2}$ Using these World Health Organization criteria, the anemia prevalence ranges from $8.1 \%$ to $24.7 \%$ in community-dwelling older persons, $31 \%$ to $60 \%$ in nursing home patients and $40 \%$ to $72 \%$ in hospitalized older patients. ${ }^{3-7}$ Anemia in older patients is recognized as a risk factor for negative outcomes, such as reduced physical performance and muscle strength, falls and fractures, hospitalization, cognitive impairment, depression, and mortality. ${ }^{3,5,8-15}$

Anemia related to iron deficiency (iron restricted erythropoiesis, independent of the iron stores) can be associated with iron deficiency anemia (IDA; absent iron stores), iron sequestration (normal or increased

Accepted for publication 31 August 2017.

Correspondence: Dr Etienne Joosten MD PhD, Division of

Geriatric Medicine, University Hospitals Leuven, Herestraat

49, B-3000 Leuven, Belgium. Email: etienne.joosten@uzleuven.be iron stores, anemia of inflammation [AI]) and functional iron deficiency (treatment with erythropoiesis stimulating agents). ${ }^{16}$ The differential diagnosis between IDA and AI is sometimes difficult because of the aspecific symptomatology, multimorbidity and difficulties in the interpretation of the biochemical iron parameters. During the past decades, a great deal of research has been carried out in the field of the pathophysiology of iron homeostasis, more specifically the role of hepcidin, resulting in novel diagnostic laboratory analyses. ${ }^{17,18}$ IDA is an important disease in older adults because of the potential underlying disorders, such as gastrointestinal ulcers and tumors, arteriovenous malformations, and malabsorption disorders. The aim of the present article was to provide an overview of the optimal diagnostic strategy, investigation and treatment of absolute IDA in older adults.

\section{Pathophysiology of iron metabolism}

The human body contains 3-4 g of iron, of which $70 \%$ is incorporated into the hemoglobin of the red blood cells. The average daily iron uptake, $1-2 \mathrm{mg}$, is balanced out by iron loss as the result of sweating, loss of epithelial cells of the skin, and mucosal cells of the 
gastrointestinal and genitourinary tract. Plasma contains $2-4 \mathrm{mg}$ of iron, bound to serum transferrin. For the production of red blood cells and body metabolism, $20-25 \mathrm{mg}$ of iron is required on a daily basis and therefore, iron recycling from aging red blood cells is necessary. Dietary iron is available in the heme $(\mathrm{Fe} 2+$ or ferrous iron) and the non-heme form ( $\mathrm{Fe} 3+$ or ferric iron). A review about intestinal iron absorption can be found elsewhere. ${ }^{19-21}$ Hepcidin plays a central role in iron homeostasis by inhibiting both the iron transport from the enterocytes into the plasma in the proximal duodenum, as well as the release of iron from the body iron stores. The serum hepcidin levels are low in patients with IDA, and this results in elevated intestinal iron absorption and release of iron from the macrophages. In inflammatory disorders, hepcidin production is stimulated by an increased interleukin- 6 production in the liver, and this blocks the intestinal iron absorption and the release of iron from the body stores. $^{17,18,20,22}$

\section{Symptoms and clinical presentation}

Older patients with IDA are often asymptomatic and the diagnosis is made during a routine blood analysis. Symptoms and signs can be aspecific as a result of anemia, such as fatigue, paleness, dyspnea, angina pectoris and edema, or more specifically related to IDA, such as koilonychia, pica and atrophic glossitis. ${ }^{23,24}$ There is also some evidence that IDA is associated with restless legs syndrome in geriatric patients. ${ }^{25}$ Chronic blood loss, such as hematuria, and hemorrhoidal and gynecological blood loss, are mostly obvious causes associated with IDA. In specific cases, the combination of symptoms and clinical signs, such as melena and abdominal pain or malabsorption and diarrhea, are suggestive for a specific underlying cause, such as colonic cancer or celiac disease, respectively. ${ }^{26}$

\section{Diagnosis and epidemiology of IDA}

The diagnosis of IDA remains a challenge for the clinician. Neither a standardized test or set of tests, nor generally accepted decision limits and reference intervals for each specific test exist. ${ }^{19,22,23}$ Furthermore, the underlying cause for the IDA is often multifactorial in older patients. ${ }^{27}$ Several non-invasive laboratory tests are available, and each test requires a thorough knowledge of its pros and cons before a proper interpretation of its contribution to the diagnosis of IDA is possible. The red blood cell indices have limited information, and the mean corpuscular volume can be microcytic or normocytic in IDA patients, while microcytic anemia can also occur in patients with $\mathrm{AI}^{23,28}$ Serum iron, transferrin and the calculated transferrin saturation are widely used, but are not diagnostic for IDA. ${ }^{23,28,29}$
Table 1 Laboratory criteria for the differential diagnosis between iron deficiency anemia and anemia of inflammation in older patients

\begin{tabular}{lcc}
\hline & IDA & AI \\
\hline Serum iron & $\downarrow$ & $\downarrow$ \\
Serum transferrin & $\mathrm{nl}$ or $\uparrow$ & $\downarrow$ or $\mathrm{nl}$ \\
Transferrin saturation & $<25 \%$ & $<25 \%$ \\
Serum ferritin & $<50 \mu \mathrm{g} / \mathrm{L}$ & $>100 \mu \mathrm{g} / \mathrm{L}$ \\
Serum transferrin receptor & $\uparrow$ & $\downarrow$ \\
Serum hepcidin & $\downarrow \downarrow$ & $\uparrow$ \\
\hline
\end{tabular}

$\mathrm{AI}$, anemia of inflammation; IDA, iron deficiency anemia; $\mathrm{nl}$, normal. For most laboratory tests, there are no generally accepted decision limits (the values presented in the table are from Joosten ${ }^{28}$ ).

Serum ferritin as an indicator for the assessment of iron stores is also widely available, well standardized and currently the most used parameter to diagnose IDA. However, it is an acute phase reactant, and its serum level increases with age. ${ }^{30-32} \mathrm{~A}$ broad range of ferritin thresholds up to $100 \mu \mathrm{g} / \mathrm{L}$ and even higher have been proposed in many older and recent studies depending on age, sex, patient selection and specific disease categories (i.e. absolute IDA, chronic kidney disease, cancer, chronic heart failure and other inflammatory disorders) and treatment options (i.e. erythropoietin stimulating agents in combination with iron therapy). As a consequence, it remains unclear in older patients which cut-off point is the most appropriate for the diagnosis of IDA and the differential diagnosis with other causes, especially AI (Table 1). In older patients, a serum ferritin $<50 \mu \mathrm{g} / \mathrm{L}$ is highly suggestive of iron deficiency. ${ }^{33,34}$ To what extent the association of a low transferrin saturation to the serum ferritin level might increase the diagnostic accuracy for iron deficiency is unclear. A low transferrin saturation suggests an inadequate iron supply for red blood cell production, and is also often found in patients with $\mathrm{AI} .{ }^{28} \mathrm{~A}$ combination of non-iron related parameters, such as C-reactive protein and the erythrocytic sedimentation rate, as markers of inflammation can be useful to estimate the effect of inflammation in IDA patients, but it is not exactly known which cut-off points should be used. ${ }^{30,31,35}$ Indeed, many older patients with IDA and a serum ferritin level $<20 \mu \mathrm{g} / \mathrm{L}$ have an elevated C-reactive protein level or erythrocytic sedimentation rate. ${ }^{27}$ In recent years, a better understanding of the pathophysiology of the iron homeostasis has led to the introduction of newer laboratory analyses, such as serum transferrin receptor (sTfR), reticulocyte hemoglobin content or reticulocyte hemoglobin equivalent and serum hepcidin. ${ }^{36}$ The sTfR has the potential advantage over serum ferritin that it lacks an acute phase component. ${ }^{36} \mathrm{How}-$ ever, the sTfR and sTfR over serum ferritin ratio are not widely available, and the assay is not standardized. 
In a recent meta-analysis, the sTfR assay had a sensitivity of $86 \%$ and a specificity of $75 \%$, and our previously published research found serum ferritin superior to sTfR for the diagnosis of IDA in older patients. ${ }^{37,38}$

Reticulocyte hemoglobin content and reticulocyte hemoglobin equivalent, as an early sign of functional iron deficiency, can easily be generated by automated cell counters, but its diagnostic usefulness in older patients with IDA is limited. ${ }^{29,39-41}$ Hepcidin levels are elevated in patients with acute or chronic inflammatory anemia, and are low in patients with IDA. ${ }^{17,18}$ This biomarker is not yet routinely available, and variability in measurements between different laboratories has hampered the identification of uniform cut-offs for serum hepcidin. The results of a few studies in older patients are conflicting, but it is a promising laboratory test for the diagnosis of iron disorders. ${ }^{42-45}$

When iron malabsorption is suspected (celiac disease, gastritis, Helicobacter pylori), an oral iron absorption test can be carried out after an oral iron load. This test is not validated, multiple oral iron doses are used and the interpretation of the results is not standardized. However, it is a non-invasive test that can provide some limited additional information. ${ }^{46,47} \mathrm{~A}$ bone marrow smear with Prussian blue is generally considered as the gold standard investigation for the diagnosis of iron deficiency, but it is invasive and uncomfortable for the patient, the interpretation can vary significantly between investigators, and it is in general not a part of the diagnostic work-up of the anemic older patient. ${ }^{48}$

Given the lack of consensus on the diagnosis of IDA, one should not be surprised that the prevalence of IDA in an older population varies widely within various subgroups. IDA was diagnosed in $16.6-25 \%$ of non-hospitalized older adults, $22-40 \%$ of institutionalized older adults and $15-65 \%$ of hospitalized older adults. ${ }^{5-7,49,50}$ Even more problematic is the diagnosis of the combination of IDA and AI for which no clear laboratory diagnostic criteria for older adults are available. ${ }^{27}$

\section{Additional investigations and etiology}

History (hematemesis, melena, hematuria, uterine blood loss, weight loss, previous gastrointestinal surgery), drug use (non-steroidal anti-inflammatory drugs, aspirin, anticoagulans, corticosteroids, proton pump inhibitors) and clinical examination remain the cornerstone of the initial approach to the older patient with IDA. $^{23,24,26}$ The main causes for IDA in older patients are chronic blood loss and iron malabsorption, whereas the role of a reduced dietary iron intake is still unclear (Table 2). ${ }^{54,55}$ However, $85 \%$ of patients with IDA (mean age 59 years), but without gastrointestinal symptoms, that were investigated with a gastroscopy
Table 2 Common diseases associated with iron deficiency anemia in elderly patients

Chronic blood loss
Esophagitis and gastritis
Gastric and duodenal ulcer
Esophageal and gastric cancer
Large hiatal hernia
Angiodysplasia
Colonic cancer
Colonic polyps
Hematuria
Uterine bleeding
Drugs (non-steroidal inflammatory drugs, salicylates,
anticoagulants)
Malabsorption
Helicobacter pylori
Autoimmune gastritis
Celiac disease
Proton pump inhibitors

Adapted from Lopez et al. ${ }^{23}$, Goddard et al. ${ }^{26}$, Rockey and Cello $^{51}$, Joosten et al. ${ }^{52}$ and Hershko and Camaschella ${ }^{53}$ with permission.

and colonoscopy had a likely cause for IDA, and non-bleeding (atrophic gastritis, celiac disease, H. pylori gastritis) was more frequent than bleeding-associated diseases (peptic ulcer, cancer, hiatal hernia, vascular ectasia). ${ }^{56}$ Urogenital blood loss, as in renal cancer or bladder cancer, can cause IDA. In most cases, this is clinically evident or can be found by testing the urine for blood. Gastrointestinal bleeding is the predominant cause to explain IDA. ${ }^{26,51}$ Given the strong association between gastrointestinal disorders and IDA, endoscopic examination of the upper and lower gastrointestinal tract should be considered in older patients with IDA unless there is an overt non-gastrointestinal explanation for the blood loss. The preparation and the investigation by means of a colonoscopy is often burdensome in older patients, without a clear therapeutic benefit in a significant number of patients because of poor general condition as a result of frailty, Alzheimer's dementia, terminal heart failure, lack of cooperation, palliative setting and refusal by the patient or their proxy. A computed tomography (CT) colonography (virtual colonoscopy) does not involve an endoscope, but requires bowel preparation. It can be useful in selected patients, but its diagnostic accuracy in older patients with IDA is unclear. ${ }^{26}$ Older patients with unexplained IDA after a routine upper and lower gastrointestinal endoscopy have a favorable outcome. ${ }^{57}$ In a retrospective study, a mixed group of 471 ambulant and hospitalized adults aged $\geq 80$ years with IDA was investigated, of which 276 patients $(59 \%)$ did not undergo any diagnostic investigation of the gastrointestinal tract. ${ }^{58}$ The authors stated that 
omission of additional diagnostic procedures did not appear to be associated with comorbidity, and not investigating patients with IDA seems appropriate depending on the therapeutic consequences, life expectancy and relevant comorbidity. It remains sometimes difficult to prove that a potential lesion found during an endoscopic investigation also effectively causes IDA, and there is also some uncertainty as to which benign lesions, such as erosive gastritis, small polyps and ulcers, might effectively be the cause of IDA. In a previously published study, we investigated 151 older patients with iron deficiency with and without anemia. ${ }^{52}$ A potential lesion was found in 47 out of the 96 patients with IDA, of which 32 were benign lesions and 15 were cancers (2 gastric cancers, 13 colonic cancers), whereas 31 out of the 55 nonanemic patients with iron deficiency had a potential gastrointestinal lesion; 23 benign and eight cancers (1 esophageal, 2 gastric and 5 colonic cancers). As a consequence, endoscopic investigation can also be considered in older iron-deficient patients without anemia. ${ }^{52}$

The approach to a gastrointestinal investigation is population-specific, and one has to consider first to what extent that investigation will change the therapeutic and prognostic options, taking into account the increased risk of complications in this vulnerable patient group. Small bowel capsule endoscopy can be considered as the next step in the investigation of patients with IDA with a negative esophagogastroduodenoscopy and colonoscopy. Common small bowel lesions seen on capsule endoscopy in older patients are angiodysplasia and ulcerations, whereas cancer, inflammatory bowel disease and celiac disease are less common. However, most of the studies on capsule endoscopy were carried out in highly selected patient groups. A substantial number of patients found the capsule endoscopy study very tiresome and difficult; the diagnostic yield in older patients with IDA varies between $53 \%$ and $72 \%$, but the related therapeutic options are mostly limited. ${ }^{59-62}$ Hence, a capsule endoscopy should only be carried out in selected cases of older patients. The figure shows the flow chart for gastrointestinal investigation of older patients with IDA in University Hospitals Leuven, Leuven, Belgium (Fig. 1).

Most patients with IDA and a negative upper and lower gastrointestinal endoscopy have a favorable outcome without further investigation, especially when the anemia resolves after treatment. ${ }^{63}$ Other investigations, such as an abdominal CT scan, are less invasive and can be carried out as an alternative when endoscopic investigations are not indicated, but this investigation has a low sensitivity for IDA-associated lesions. Gastrointestinal causes of IDA that are associated with iron malabsorption, such as atrophic gastritis, H. pylori and

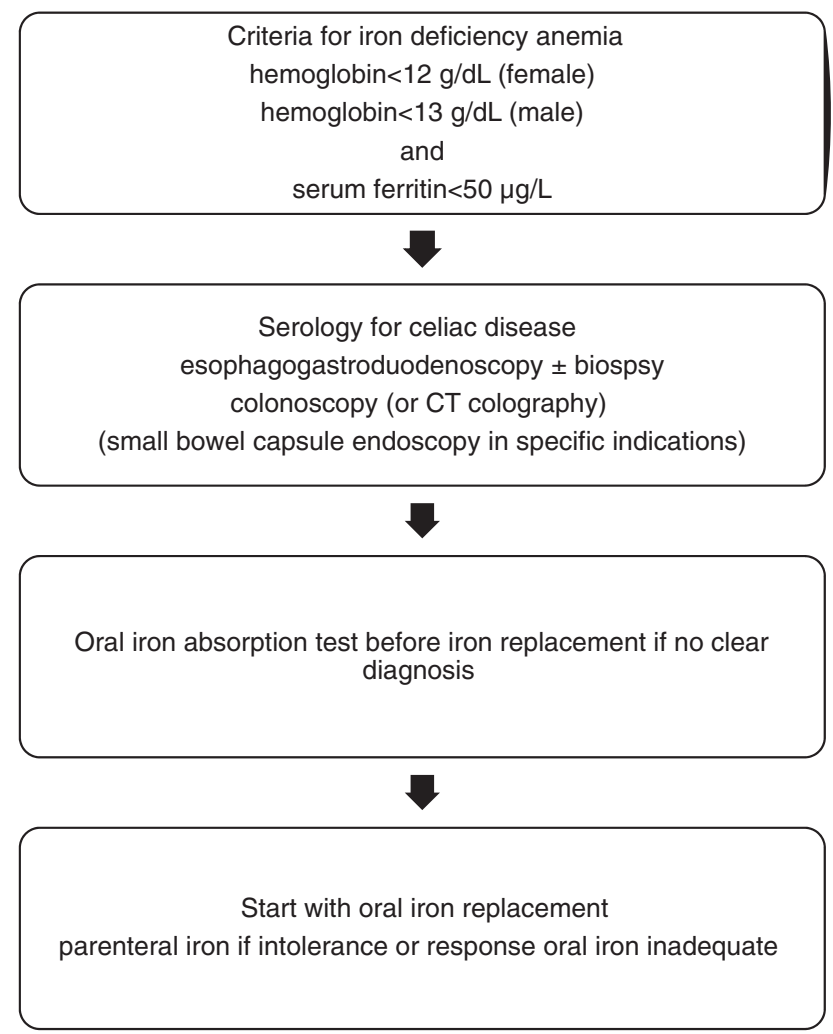

Figure 1 Flow chart for the gastrointestinal investigation of older patients with iron deficiency anemia. CT, computed tomography.

celiac disease, are important, but their detailed contribution to IDA in an elderly population is not well known. ${ }^{53}$

\section{Treatment}

The treatment primarily consists of iron replacement, either orally or parenterally. The total iron dose supplementation can be calculated according to specific formulas, such as the Ganzoni formula (target hemoglobin [g/dL] - actual hemoglobin [g/dL] $\times 2.4 \times$ bodyweight $[\mathrm{kg}]+500 \mathrm{mg}$ ) or specific guidelines as proposed by the manufacturer, but there is no standard iron calculation for the most appropriate iron deficit dose. ${ }^{64}$ A large number of oral iron formulations are widely available, and the most commonly prescribed preparations are ferrous sulphate, gluconate and fumarate. It is still unclear whether there is a difference between the different preparations in terms of hematological efficacy and adverse events. ${ }^{19,23,24,26,65-67}$ The recommended daily iron dose for adults varies, and is usually between 60 and $200 \mathrm{mg}$ elementary iron, with or without vitamin $\mathrm{C}$ to improve the iron absorption, in one to three daily doses. However, recent research has shown that oral iron supplement at doses of $\geq 60 \mathrm{mg}$ increases serum hepcidin for up to $24 \mathrm{~h}$, and is associated with 
lower iron absorption the next day. ${ }^{68}$ An analog phenomenon of "mucosal block" was already shown in 1987 with the small-dose iron tolerance test. ${ }^{69}$ These findings might support the administration of lower oral iron dosages and alternate day supplementation. Evidence for this was found in a previous study where the oral administration of $15 \mathrm{mg}$ and $50 \mathrm{mg}$ of elemental iron on a daily basis was shown to be as effective as a dose of $150 \mathrm{mg}$ in older IDA patients, but with fewer adverse events. ${ }^{70}$ A treatment duration of 3-6 months is usually required for the repletion of the iron stores, but an increase in serum ferritin level up to $100 \mu \mathrm{g} / \mathrm{L}$ or more is a good alternative end-point. The side-effects are well-known, and include nausea, constipation, diarrhea, abdominal discomfort and black stools. ${ }^{23}$ The absence of a significant response to oral iron supplementation can be attributed to a IDA misdiagnosis, malabsorption or persistent chronic blood loss that exceeds the amount of iron that can be absorbed from an oral supplement. ${ }^{53}$ Patients with intolerance to oral iron, malabsorption or chronic blood loss might benefit from parenteral iron. ${ }^{23,24,26,53,71}$ Several parenteral iron preparations are available, and the most commonly prescribed preparations are iron sucrose, ferric carboxymaltose and iron dextran. ${ }^{24}$ The total iron dose to replete the iron stores can be provided in one or a few more sessions depending on the formula used, it is safe but more expensive than oral iron. There is insufficient evidence that one iron preparation is superior over another, and the efficacy and safety of parenteral ferric carboxymaltose has been shown in heterogeneous groups of older patients. ${ }^{24,65,72-75}$ The results of iron therapy for indications other than absolute IDA, such as cancer-related anemia, chronic kidney disease, chronic heart failure, inflammatory anemia and postoperative anemia, are not discussed here. There are insufficient data to decide whether iron deficiency (low serum ferritin level with normal hemoglobin value) in older adults should be treated with iron. The administration of intramuscular injections of iron should be avoided, as it can cause local pain, discoloration of the skin and a higher risk of anaphylactic shock.

\section{Conclusion}

Absolute IDA is a common problem in older patients. There are no standard diagnostic criteria, but in our opinion, a low serum ferritin (i.e. $<50 \mu \mathrm{g} / \mathrm{L}$ ) is a simple and well validated diagnostic criterion for IDA. A transferrin saturation $<20 \%$ and other laboratory analyses, such as reticulocyte hemoglobin content or reticulocyte hemoglobin equivalent and STfR, can provide additional information. Recent research regarding hepcidin as a central regulator of iron homeostasis is promising for the future, but has not yet been used for the routine diagnosis of IDA. Once the diagnosis of IDA is made, an esophagogastroduodenoscopy and colonoscopy should be initiated in order to identify the underlying cause of bleeding. CT colonography can replace a colonoscopy, and in specific cases, a video capsule is recommended. It remains crucial to keep in mind which potential benefits might be expected from these investigations in this vulnerable patient population, and one should discuss the pros and cons with the patient, a family member or a proxy. Oral iron administration is the standard treatment, but parenteral iron is a convenient and relatively safe way to provide the total iron dose in one or a few sessions. In the case of negative findings, we propose an oral iron absorption test and await the outcome of a trial with iron supplementation.

\section{Acknowledgements}

The author is grateful to Martin Hiele MD $\mathrm{PhD}$, Department of Gastroenterology of the University Hospitals Leuven, Belgium, for reviewing the manuscript.

\section{Disclosure statement}

The author declares no conflict of interest.

\section{References}

1 Blanc B, Finch CA, Hallberg L et al. Nutritional anaemias. Report of a WHO Scientific group. WHO Tech Rep Ser 1968; 405: 1-40.

2 Nilsson-Ehle H, Jagenburg R, Landahl S, Svanborg A. Blood haemoglobin declines in the elderly: implications for reference intervals from age 70 to 88. Eur J Haematol 2000; 65: 297-305.

3 Beghé C, Wilson A, Ershler WB. Prevalence and outcomes of anemia in geriatrics: a systematic review of the literature. Am J Med 2004; 116 (Suppl): 3S-10S.

4 Gaskell H, Derry S, Moore R, McQuay H. Prevalence of anaemia in older persons: systematic review. BMC Geriatr 2008; 8: 1-8.

5 Guralnik JM, Eisenstaedt RS, Ferrucci L, Klein HG, Woodman RC. Prevalence of anemia in persons 65 years and older in the United States: evidence for a high rate of unexplained anemia. Blood 2004; 104: 2263-2268.

6 Joosten E, Pelemans W, Hiele M, Noyen J, Verhaeghe R, Boogaerts MA. Prevalence and causes of anaemia in a geriatric hospitalized population. Gerontology 1992; 38: 111-117.

7 Artz AS, Fergusson D, Drinka PJ et al. Mechanisms of unexplained anemia in the nursing home. J Am Geriatr Soc 2004; 52: 423-427.

8 De la Cruz-Góngora $\mathrm{V}$, Manrique-Espinoza B, Villalpando S, Téllez-Rojo Solís MM, SalinasRodriguez A. Short-term impact of anemia on mortality: evidence from a sample of Mexican older adults. J Aging Health 2014; 26: 750-765.

9 Hong $\mathrm{CH}$, Falvey C, Harris TB et al. Anemia and risk of dementia in older adults: findings from the Health $\mathrm{ABC}$ study. Neurology 2013; 81: 528-533.

10 Peters R, Burch L, Warner J, Beckett N, Poulter R, Bulpitt C. Haemoglobin, anaemia, dementia and cognitive 
decline in the elderly, a systematic review. BMC Geriatr 2008; 8: 18 .

11 Zakai NA, Katz R, Hirsch C et al. A prospective study of anemia status, hemoglobin concentration, and mortality in an elderly cohort. The cardiovascular health study. Arch Intern Med 2005; 165: 2214-2220.

12 Izaks G, Westendorp R, Knook D. The definition of anemia in older persons. JAMA 1999; 281: 3-6.

13 Joosten E, Lemiengre J, Nels T, Verbeke G, Milisen K. Is anaemia a risk facgtor for delrium in an acute geriatric population? Gerontology 2006; 52: 382-385.

14 Hirani V, Naganathan V, Blyth F et al. Low hemoglobin concentrationa are associatede with sarcopenia, physical performance, and disability in older Australian men in cross-sectional and longitudinal analysis. J Gerontol A Biol Sci Med Sci 2016; 71: 1667-1675.

15 Penninx BWJH, Pahor M, Woodman RC, Guralnik JM. Anemia in old age is associated with increased mortality and hospitalization. J Gerontol A Biol Sci Med Sci 2006; 61: 474-479.

16 Goodnough LT, Nemeth E, Ganz T. Detection, evaluation, and management of iron-restricted erythropoiesis. Blood 2010; 116: 4754-4761.

17 Girelli D, Nemeth E, Swinkels DW. Hepcidin in the diagnosis of iron disorders. Blood 2016; 127: 2809-2813.

18 Ganz T. Hepcidin and iron regulation, 10 years later. Blood 2011; 117: 4425-4433.

19 Camaschella C. Iron-deficiency anemia. N Engl J Med 2015; 372: 1832-1842.

20 Evstatiev R, Gasche C. Iron sensing and signalling. Gut 2012; 61: 933-952.

21 Fuqua BK, Vulpe CD, Anderson GJ. Intestinal iron absoption. J Trace Elem Med Biol 2012; 26: 115-119.

22 Weiss G, Goodnough LT. Anemia of chronic disease. N Engl J Med 2005; 352: 1011-1023.

23 Lopez A, Cacoub P, Macdaugall IC, Peyrin-Biroulet L. Iron deficiency anaemia. Lancet 2016; 387: 907-916.

24 Auerbach M, Adamson JW. How we diagnose and treat iron deficiency anaemia. Am J Hematol 2016; 91: 31-38.

25 Allen RP, Auerbach S, bahrein H, Auerbach M, Early CJ. The prevalence and impact of restless legs syndrome on patients with iron deficiency anaemia. Am J Hematol 2013; 88: 261-264.

26 Goddard AF, James MW, McIntyre AS, Scott BB. Guidelines for the management of iron deficiency anemia. Gut 2011; 60: 1309-1316. https://doi.org/10.1136/gut.2010.228874

27 Joosten E, Lioen P. Iron deficiency anemia and anemia of chronic disease in geriatric hospitalized patients: How frequent are comorbidities as an additional explanation for the anemia? Geriatr Gerontol Int 2015; 15: 931-935.

28 Joosten E. Strategies for the laboratory diagnosis of some common causes of anemia in elderly patients. Gerontology 2004; 50: 49-56.

29 Thomas DW, Hinchliffe RF, Briggs C, Macdougall IC, Littlewood T, Cavill I. Guideline for the laboratory diagnosis of functonal iron deficiency. Br J Haematol 2013; 161: 639-648.

30 Coenen JLLM, van Dieijen-Visser MP, van Pelt J et al. Measurements of serum ferritin used to predict concentrations of iron in bone marrow in anemia of chronic disease. Clin Chem 1991; 37: 560-563.

31 Witte DL, Kraemer DF, Johnson GF, Dick FR, Hamilton H. Prediction of bone marrow iron findings from tests performed on peripheral blood. Am J Clin Pathol 1986; 85: 202-206.

32 Hollowell JG, Van Assendelft OW, Gunter EW et al. Hematological and iron-related analytes-Reference data for persons aged 1 year and over: United States, 1988-94. National Center for Health Statistics. Vital Health Stat 11 2005; 247: 1-156.

33 Guyatt GH, Patterson C, Ali M et al. Diagnosis of irondeficiency anemia in the elderly. Am J Med 1990; 88: 205-209.

34 Joosten E, Hiele M, Ghoos Y, Pelemans W, Boogaerts MA. Diagnosis of iron-deficiency anemia in a hospitalized geriatric population. Am J Med 1991; 90: 653-654.

35 Thurnham DI, McCabe LD, Haldar S, Wieringa FT, Northrop-Cleves CA, McCabe GP. Adjusting plasma ferritin concentrations to remove the effecs of subclinical inflammation in the assessment of iron deficiency: a metaanalysis. Am J Clin Nutr 2010; 92: 546-555.

36 Punnonen K, Irjala K, Rajamäki A. Serum transferrin receptor and its ratio to serum ferritin in the diagnosis of iron deficiency. Blood 1997; 89: 1052-1057.

37 Infusino I, Braga F, Dolci A, Panteghini M. Soluble transferrin receptor (sTfR) and $s \mathrm{TfR} / \mathrm{log}$ ferritin index for the diagnosis of iron-deficiency anemia. A meta-analysis. Am J Clin Pathol 2012; 138: 642-649.

38 Joosten E, Van Loon R, Billen J, Blanckaert N, Fabri R, Pelemans W. Serum transferrin receptor in the evaluation of the iron status in elderly hospitalized patients with anemia. Am J Hematol 2002; 69: 1-6.

39 Brugnara C, Schiller B, Moran J. Reticulocyte hemoglobin equivalent (Ret $\mathrm{He}$ ) and assessment of iron-deficient states. Clin Lab Haematol 2006; 28: 303-308.

40 Karlsson T. Comparative evaluation of the reticulocyte hemoglobin content assay when screening for irondeficiency in elderly anemic patients. Anemia 2011; 2011: 925907.

41 Joosten E, Lioen P, Brusselmans C, Indevuyst C, Boeckx N. Is analysis of the reticulocyte haemoglobin equivalent a useful test for the diagnosis of iron-deficiency anaemia in geriatric patients? Eur J Intern Med 2013; 24: 63-66.

42 Karlsson T. Mass spectrometry evaluation of the hepcidin25 assay in the differential diagnosis of iron-deficiency anaemia with concurrent inflammation and anaemia of inflammation in elderly patients. Eur J Haematol 2015; 95: 467-471.

43 Geerts I, Vermeersch P, Joosten E. Evaluation of the first commercial hepcidin ELISA for the differential diagnosis of anemia of chronic disease and iron-deficiency anemia in hospitalized geriatric patients. ISRN Hematol 2012; 2012: 567491.

44 Shu $\mathrm{T}$, Jing $\mathrm{C}, \mathrm{Lv} \mathrm{Z}$, Xie $\mathrm{Y}, \mathrm{Xu} \mathrm{J}, \mathrm{Wu}$ J. Hepcidin in tumor-related iron deficiency anemia and tumor-related anemia of chronic disease: pathogenic mechanisms an diagnosis. Eur J Haematol 2014; 94: 67-73.

45 Ferrucci L, Semba RD, Guralnik JM et al. Proinflammatory state, hepcidin, and anemia in older persons. Blood 2010; 115: 3810-3816.

46 Joosten E, Vander Elst B, Billen J. Small-dose oral iron absorption test in anaemic and non-anaemic elderly hospitalized patients. Eur J Haematol 1997; 58: 99-103.

47 Joosten E. What is the clinical significance of the oral iron absorption test for the elderly? J Nutr Health Aging 2005; 9: 387-389.

48 Barron BA, Hoyer JD, Tefferi A. A bone marrow report of absent stainable iron is not diagnostic of iron-deficiency. Ann Hematol 2001; 80: 166-169.

49 Artz AS, Thirman MJ. Unexplained anemia predominates despite an intensive evaluation in a racially diverse cohort of older adults from a referral anemia clinic. $J$ Gerontol A Biol Sci Med Sci 2011; 66: 925-932. 
50 Geisel T, Martin J, Schulze B et al. An etiologic profile of anemia in 405 geriatric patients. Anemia 2014; 2014: 932486. https://doi.org/10.1155/2014/932486

51 Rockey D, Cello J. Evaluation of the gastrointestinal tract in patients with iron-deficiency anemia. $N$ Engl J Med 1993; 329: 1691-1695.

52 Joosten E, Ghesquiere B, Linthoudt $\mathrm{H}$ et al. Upper and lower gastrointestinal evaluation of elderly inpatients who are iron deficient. Am J Med 1999; 107: 24-29.

53 Hershko C, Camaschella C. How I treat unexplained refractory iron-deficiency anemia. Blood 2014; 123: 326-333.

54 Milman N, Pedersen AN, Ovesen L, Schrol M. Irn status in 358 apparently halthy 80-year old Danish men and women: relation to food composition and dietary and supplemental iron intake. Ann Hematol 2004; 83: 423-429.

55 Lopez-Contreas MJ, Zamoro-Portero S, Lopez MA, Marin JF, Zamora S, Perez-Llamas F. Dietary and iron status of insttutionalized elderly people: relationship with different factors. J Nutr Health Aging 2010; 10: 816-821.

56 Annibale B, Capuro G, Chistolini A et al. Gastrointestinal causes of refractory iron deficiency anemia in patients without gastrointestinal symptoms. Am J Med 2001; 111: 439-445.

57 Nahon S, Lahmek P, Barclay F et al. Long-term follow-up and predictive factors of recurrence of anemia in a cohort of 102 very elderly patients explored for iron-deficiency anemia. J Clin Gastroenterol 2008; 42: 984-990.

58 Hamaker ME, Acampo T, Remijn JA et al. Diagnostic choices and clinical outcomes in octogenarians and nonagenarians with iron-deficiency anemia in the Netherlands. J Am Geriatr Soc 2013; 61: 495-501.

59 Muhammad A, Vidyarthi G, Brady P. Role of small bowel capsule endoscopy in the diagnosis and management of iron deficiency anemia in the elderly: a comprehensive review of the current literature. World J Gastroenterol 2014; 20: $8416-8423$.

60 Koulaouzidis A, Rondonotti E, Giannakou A, Plevris JN. Diagnostic yield of small-bowel capsule endoscopy inpatients with iron-deficiency anemia: a systematic review. Gastrointest Endosc 2012; 76: 983-992.

61 Tsibouris P, Kalantzis C, Apostolopoulos P, Alexandrakis G, Mavrogianni P, Kalantzis N. Capsule endoscopy findings in patients with occult or overt bleeding older than 80 years. Dig Endosc 2012; 24: 154-158.

62 Girelli CM, Maiero S, Porta P, Cannizzaro R. Small bowel capsule endoscopy performance in octogenarians: a casecontrol study. J Gerontol A Biol Sci Med Sci 2011; 66A: 68-73.
63 Soon A, Cohen BL, Groessl EJ, Ho SB. Long-term outcomes and prognostic factos for patients with endoscopynegative iron deficiency. Dig Dis Sci 2013; 58: 488-495.

64 Ganzoni A. Intravenous iron-dextran: therapeutic and experimental possibilities. Schweiz Med Wochenschr 1970; 100: 301-303.

65 Clevenger B, Gurusamy K, Klein AA, Murphy GJ, Anker SD, Richards T. Systematic eview and meta-analysis of iron therapy in anemic aduls without chronic kidney disease: updated and abridged Cochrane review. Eur J Heart Fail 2016; 18: 774-785.

66 Cancelo-Hidalgo MJ, Castelo-Branco C, Palacios S et al. Tolerability of different oral iron supplements: a systematic review. Curr Med Res Opin 2013; 29: 291-303.

67 Alleyne M, Horne M, Miller J. Individualized treatment for iron-deficiency anemia in adults. Am J Med 2008; 121: 943-948.

68 Moretti D, Goede JS, Zeder C et al. Oral iron supplements increase hepcidin and decrease iron absorption from daily or twice-daily dosis in iron-depleted young women. Blood 2015; 126: 1981-1989.

69 O'Neil-Cutting MA, Crosby WH. Blocking of iron absorption by a preliminary oral dose of iron. Arch Intern Med 1987; 147: 489-491.

70 Rimon E, Kagansky N, Kagansky M et al. Are we giving too much iron? Low-dose iron therapy is effective in octogenarians. Am J Med 2005; 118: 1142-1147.

71 Camaschella C. New insights into iron deficiency and iron deficiency anemia. Blood Rev 2017; 31: 225-233 https://doi. org/10.1016/j.blre.2017.02.0043

72 Anker S, Colet JC, Filippatos G et al. Ferric carboxymaltose in patients with hert failue and iron deficiency. $N$ Engl J Med 2009; 361: 2436-2448.

73 Khalafallah AA, Yan C, Al-Badri R et al. Intravenous ferric carboxymaltose versus standard care in the managementof pmostoperative anaemia: a prospective, open-label, randomised controlled trial. Lancet Haematol 2016; 3: e415-e425.

74 Ponikowski $\mathrm{P}$, van Veldhuisen DJ, Comin-Colet J et al. Beneficial effects of long-term intravenous iron therapy with ferric carboxymaltose in patients with symptomatic heart failure and iron deficiency. Eur Heart J 2015; 36: 657-668.

75 Bach M, Geisel T, Martin J et al. Efficacy and safety of intravenous ferric carboxymaltose in geriatric inpatients at a german tertiary uiversity teaching hospital: a retrospective observational cohort study of clinical practice. Anemia 2015; 2015: 647930 https://doi.org/10.1155/2015/647930 